\title{
Money Matters: a Nuanced Approach to Understanding the Relationship between Household Income and Child Subjective Well-Being
}

\author{
Gill Main ${ }^{1}$ (D)
}

Accepted: 10 June 2018 / Published online: 27 June 2018

(C) The Author(s) 2018

\begin{abstract}
This paper examines the links between household income and child subjective well-being. Previous studies produce contradictory findings: qualitative investigations indicate a strong relationship which is elusive in quantitative studies. I hypothesise that the reason for this discrepancy is that household-level measures of child poverty do not adequately capture children's active roles in forming views on their material needs, assessing their comparative socio-economic status, and contributing to processes and outcomes of intra-household resource sharing. Thus a relationship between household income and subjective well-being is hypothesised to exist, but to be mediated by factors including (among others) material deprivation, perceptions of fairness in the processes and outcomes of intra-household allocation, and subjective material well-being. Drawing on survey data from a sample of 1010 parent-child (aged 10-16) pairs in England, structural equation modelling is used to examine these potential mediating effects. Findings indicate that income has a complex role to play in child subjective well-being, with significant direct and indirect associations. Income, deprivation, perceptions of the fairness of intra-household allocation processes and outcomes, and subjective material well-being are all significantly interrelated and are all predictors of subjective well-being. The complex nature of these relationships illustrates the multi-dimensional nature of child poverty and its impacts. Household income is an important factor; but alone it cannot capture children's active roles in assessing their needs and material living conditions. This confirms the importance of considering children's agency in understandings of child poverty and material well-being, and including their reports in studies of child poverty and intra-household allocation.
\end{abstract}

Keywords Child poverty · Income $\cdot$ Subjective well-being Intra-household allocation · children's agency

Gill Main

G.main@leeds.ac.uk

1 School of Education, University of Leeds, Leeds, UK 


\section{Introduction}

The importance of household income as a predictor of negative outcomes for children and for the adults children become is well established (e.g. see Cooper and Stewart 2013). However, recent research focusing on the links between household income and child subjective well-being has presented a contradictory picture. Qualitative research highlights experiences of shame and misery among children as a result of living in poverty (Ridge 2002; The Children's Society 2017a, b); while quantitative studies find minimal or no associations between household income and child subjective well-being (Knies 2011; Rees et al. 2011; Main 2013). Using non-income measures of deprivation based on children's own perspectives on their needs improves the explanatory power of statistical models (Main 2013); but given that money is the most common means of acquiring resources, the question remains as to why household income is repeatedly found to be a minimally important or non-significant factor. Building on Cummins' (2000) hypothesis that the effects of income on subjective well-being are mediated by more concrete material and social factors, I examine whether a more nuanced approach to understanding the pathways via which household income is associated with individual subjective well-being can help in addressing this question. Such an approach should incorporate children's perspectives on their needs, their material living standards, and how resources are shared within their families. This research is informed by literature from four fields: studies of childhood; of poverty; of intra-household allocation; and of subjective well-being. These are discussed next, followed by details of the data and methods, the analysis, and a discussion of the findings with suggestions for future research to continue the development of this small but growing field of study.

\section{Background}

\subsection{The Study of (Child) Poverty}

It is well-established that child poverty has wide-ranging negative impacts on children's lives during childhood, and for the adults children become (Griggs and Walker 2008; Bradshaw 2016). An important consideration in understanding child poverty, in addition to how it impacts children's lives, is how it can best be conceptualised and measured. Different concepts lead to different kinds of measure, which can produce very different results (e.g. see Bradshaw and Finch 2003) - and indeed we may not expect strong overlaps between measures designed to capture different dimensions of poverty. The growing consensus that poverty is a multidimensional concept has resulted in a proliferation of studies concerned with how best to reflect this in approaches to measurement, and an acknowledgement that low household income alone cannot provide a full picture. Such a consensus is, however, notably absent in the indicators produced by these studies; different approaches emphasise different theories, definitions, and measures of poverty.

Broadly speaking, three dominant approaches to multidimensional child poverty measurement comprise relative deprivation approaches, capabilities approaches, and rights-based approaches. Relative deprivation approaches draw on Townsend's (1979) 
conception of poverty as lacking the resources necessary to participate in the society to which someone belongs. Here, poverty (a lack of control over the means of acquiring resources, usually interpreted as an adequate level of money) leads to deprivation (a lack of resources), resulting in social exclusion (being unable to participate in society in ways which are socially acceptable and condoned). This approach has been operationalised through establishing popular consensus on the material and social necessities of life, then exploring patterns in access to these necessities alongside income levels (e.g. Mack and Lansley 1985; Pantazis et al. 2006; Dermott and Main 2018). The capabilities approach draws on Sen's (1985) conception of poverty as lacking capabilities or freedoms - that is, (not) being able to choose how to access resources in a manner that permits a life someone has reason to value (Sen 1999). Money and resources - which would be described within this approach as 'functionings' or the things that people (do not) have or do - are a means to the end goal of capabilities or freedoms - having the choices necessary to live a valued life. In practice, operationalisations of the capabilities approach tend to generate similar data to the relative deprivation approach (see, for example, Alkire 2015), although Gordon and Nandy (2012) critique much of this research on the grounds that measures lack a theoretical basis. The rights-based approach draws on the 1989 United Nations Convention on the Rights of the Child (UNCRC). This approach is not underpinned by a specific theory of poverty, but rather by the standards which have been agreed as basic entitlements of all children, underpinned by overwhelming international consensus and policy action. Poverty, within this approach, results from the failure to realise children's rights in relation to provision, protection, and participation. Redmond (2008) highlights some of the challenges and advantages of a rightsbased approach to child poverty, especially in relation to provision rights (as enshrined in Article 27 of the UNCRC); and such an approach has been operationalised using UNICEF's Multiple Overlapping Deprivation Approach in various international contexts (for example see Chzhen and Ferrone 2017; Chzhen et al. 2017).

Choice, or control, is a central feature of all the approaches detailed above. Relative deprivation and capabilities approaches both stress the importance of control over resources, or capabilities, rather than resources per se. Similarly, the UNCRC which underpins rights-based approaches has five guiding principles - the definition of the child as anyone under 18 (Article 1); non-discrimination (Article 2); the child's best interests (Article 3); the right to life, survival and development (Article 6); and respect for the views of the child (Article 12). Article 12 requires adults to actively seek children's views on issues of importance to their lives, and to take these views seriously. That is, children's participation rights are a fundamental and inseparable aspect of the UNCRC. As a result, rights-based approaches should encompass a consideration of children's views - and therefore their choices - in how child poverty is defined, measured and addressed. Despite this, approaches to measuring child poverty overwhelmingly draw on theories developed around adult needs and experiences. While this has successfully highlighted myriad inequalities in vulnerability to poverty and impacts on child well-being and development, there are important tensions in transposing adult-centric theory directly onto children. Issues of choice and control are a key example of this tension. Money or income is often used as a proxy for 
freedom - with the assumption that more money translates into more freedom to access resources in line with personal preferences. This is problematic when applied to children, whose access to money and other resources is not only contingent on the level of resources available to parents or other adults, but also on how those adults choose to use such resources. This issue is rarely addressed in studies of child poverty. Usually, children are treated as passive adjuncts to parents - in relation to what poverty is, what children need, how they acquire and use resources, and who can provide reliable reports on their lives (with a few notable exceptions - Ridge 2002; Main 2013; Gross-Manos 2015; Smith and Main 2017). Such an approach faces strong challenges from social studies of children and childhood (discussed next), which emphasise children's agency.

\subsection{Childhood Studies: a Missing Link}

Social approaches to studying children and childhood have developed over the past few decades in parallel with developments in child poverty measurement, but the two fields appear to have had little communication. In contrast to developmental approaches which position children primarily as adults-in-the-making, progressing in a relatively linear fashion through ages and stages to reach the end goal of maturity - social studies position children as beings in the present who have a stake in the world not only because they will become adults, but also because they are currently children (Woodhead 2009). Children occupy a unique position as both child-beings with the right to have their opinions and preferences considered (in line with the UNCRC - see above), and adult-becomings who require the care and guidance of people older and more experienced to successfully negotiate progress towards adulthood (Uprichard 2008). As a result, children's needs may be different to those of adults. This difference is addressed in many measures of child poverty through the inclusion of child-specific indicators (e.g. Main and Bradshaw 2018; Hjelm et al. 2016; Gordon and Nandy 2012). What has been less examined, as noted in the previous section, is the fact that their 'command over resources', 'freedoms' and 'functionings' are inherently different to, and in many spheres much more constrained than, those of adults. Adults often have the power to mediate not only children's access to resources, but also the extent to which they are permitted to exercise autonomy in whether, how, and when they access resources.

Despite these constraints on children's autonomy, studies of children's lives show us that their perspectives are often complementary, and sometimes contrasting, with those of adults. Casas (2011) points out that children can provide meaningful and valuable information on their own lives and experiences, and a reliance on adult (usually parental) reports will provide a less than complete representation of these. Beginning to incorporate children's perspectives into theorising and measuring child poverty has the potential to contribute not only to understanding poverty as a problem, but also to fulfilling children's participation rights. Thus drawing on social studies of childhood to inform and reinterpret existing theories of poverty may help to develop a fuller understanding of child poverty and its impacts. This requires an unpacking of the dominant assumption that children's experiences of poverty are subsumed entirely within household experiences. Such unpacking has already revealed a great deal about the gendered nature of poverty, discussed next. 


\subsection{Poverty and Intra-Household Allocation: a Gendered and Generational Perspective}

Household income remains, in rich countries in particular, the most commonly-used indicator of poverty (Foster et al. 2013). However, it has long been established that this relies on problematic assumptions. This is not to diminish the importance of income - a wealth of evidence points to its importance for child outcomes (for a summary see Cooper and Stewart 2013). But while living in a low income household is a clear indicator that not all household members' needs can be met, the distribution of disadvantage is not necessarily equal across those members. Conversely, an 'adequate' household income does not necessarily translate into 'adequate' living standards for each member of the household at an individual level. Bradshaw (2018) discusses this issue, finding that using the benefit unit rather than the household as the unit of analysis increases the number of children found to be in poverty and alters the composition of this group; however, he notes that this approach still does not allow for inequitable sharing between family members within a benefit unit.

Bennett's (2013) overview of the literature on intra-household allocation highlights multiple inequities which have persisted since Pahl's (1989) seminal work in the field. Research has tended to focus on heterosexual couple households (with or without children), and findings include that women tend to be more likely than men to skimp on food and lack access to individual resources; are more likely to have the burden of managing budgets in low-income households while men are more likely to be responsible when resources are plentiful; are more likely to be responsible for spending on family and children; and if payments (e.g. social security payments) are made to women, money is more likely to be spent on children (Bennett 2013). More recently, researchers have pursued a generational perspective to intra-household sharing, examining resource allocation practices and outcomes between adults and children. Main and Bradshaw (2014, 2016, 2018) used nationally representative UK data to examine the distribution of resources within households containing children. Findings included that when resources are tight, adults (irrespective of gender) tend to prioritise children's needs over their own, and make substantial sacrifices to protect the children they live with. These findings echo Middleton et al.'s (1997) earlier research. However, this research remains adultcentric in that all data (on children and adults) are adult-reported. This is problematic not only because adults may not have access to all the relevant information, but also because parents and children may differ in the emphasis they place on particular resources and, therefore, on what constitutes sacrificing or meeting personal needs. Parents, from children's perspectives (Main 2013) and by their own reports (Main and Bradshaw 2018), tend to prioritise needs relating to health, education and development. Children express a strong awareness of the importance of these needs, but also highlight needs in relation to fitting in with other young people, and to having fun during childhood (Main 2013). Findings from Main's research also indicated that children believe these latter needs are often not understood or are downplayed by parents. Thus, as noted above in relation to theorising and measuring child poverty, the inclusion of children's perspectives in studies of intra-household allocation is indicated, not to supplant parental perspectives and reports but to develop a fuller picture. Household income can provide a broad picture of child poverty and its impacts; but for a deeper understanding, gathering children's own assessments of their material well-being is also necessary. 


\subsection{Subjective Well-Being and Material Well-Being}

The links between material well-being and well-being more broadly are well established (e.g. Wilkinson and Pickett 2009). The increasing interest specifically in subjective wellbeing, among both academics and policy makers, has been well documented elsewhere (e.g. Rablen 2010). Research investigating links between material conditions and subjective well-being among adults has revealed that several facets of material well-being at both individual and societal levels are associated with subjective well-being: economic security and income are both important to well-being (Headey and Wooden 2004); inequality of income within and between countries is a better predictor of subjective well-being than income itself (Wilkinson and Pickett 2009; Barrington-Leigh 2010); and individual characteristics including egalitarian preferences, perceptions of fairness, perceptions of our own position in the income distribution, and perceptions of social mobility, mediate the relationship (Katic and Ingram 2017). Thus the association between subjective well-being and material well-being for adults is important but complex.

Studies focusing on children are less prevalent. The mis-match between findings from qualitative and quantitative research is noted above, as is the increased power of measures based on children's own perspectives on their needs, in diverse national contexts (see Main and Pople (2011) in the UK; Redmond et al. (2016) in Australia; Lau and Bradshaw (2016) in Hong Kong; Gross-Manos and Ben Arieh (2016) in Israel; and Smith and Main (2017) in Canada). The four themes detailed above which were identified by Main (2013) within children's discussions of necessities - development, having fun, building relationships, and fitting in - may help to explain the similarities (primarily in relation to developmental resources) and contrasts (primarily in relation to resources needed for social inclusion - having fun and fitting in) between children's and parents' accounts of children's needs. These different emphases may help to explain the missing link between child poverty and subjective well-being in studies relying on income-based or adult-reported poverty measures. Children's emphasis on the importance of social inclusion and relationship building is likely to result in numerous mediating factors. These may include (among many others) the level of (dis)similarity between parental and child preferences and perspectives on child needs; norms within the child's social groups and spheres of experience; and the socioeconomic status of friends, peers, schools and local areas.

Another important factor is the type of measure used. Gross-Manos and Ben Arieh (2016) build on Main's (2013) finding that social inclusion is of key importance to children's understandings of deprivation and its links to subjective well-being. They use a combination of objective indicators of child deprivation and subjective indicators of social exclusion, finding stronger links between subjective well-being and subjective social exclusion, than between subjective well-being and deprivation. They conclude that social exclusion is more important to child subjective well-being than poverty. An alternative interpretation is that stronger correlations are likely to be found within variables measuring subjective facets of well-being than between objective and subjective measures relating to well-being. Goswami's (2014) finding that personality explains much of the variation in child subjective well-being would lend support to this latter interpretation: personality factors are likely to be significant predictors of children's reports in relation to a range of subjective measures, and as a result associations between two subjective measures are inherently likely to be stronger than 
those between objective and subjective measures. As a result, direct comparisons of the strength of associations between objective and subjective predictors of an outcome variable may not be particularly informative. Rather, examining the pathways by which objective predictors do (not) result in changes in subjective assessments, and how they influence variation in the associations between different subjective variables, is potentially a more fruitful avenue for investigation in relation to understanding how objective (material) conditions influence subjective well-being.

\subsection{The Interface of these Perspectives: Potential for Cross-Fertilisation}

The sections above have detailed the four broad fields of study which influence this research. Tracing these theoretical underpinnings is complex, especially as there has been limited communication between some of these fields. However, viewed together they can inform an approach to obtaining a more detailed and nuanced understanding of child poverty and its impacts. Two points of potential cross-fertilisation are particularly pertinent to this research. Firstly, the study of intra-household allocation, which problematises assumptions of equitable control over and sharing of resources, could usefully be applied to comparing differences not only between adults by gender, but also between adults and children. This may help to develop a fuller understanding of the association between material- and subjective well-being - for both adults and children. Secondly, the few studies of child poverty to date which draw on a social approach to childhood, focusing on children's perspectives and reports on poverty and material need, suggest that the treatment of children as active agents in their experiences of poverty and material well-being may be valuable in developing a more thorough and nuanced understanding of the links between material- and subjective well-being. Within this analysis, therefore, I aim to apply knowledge and theory from the social studies of childhood to the study of child poverty and intra-household allocation, in order to conduct an investigation of the complex links between household income and child subjective well-being.

\section{Research Questions and Hypotheses}

The literature reviewed above demonstrates that there are inconsistencies in findings from previous research on this topic, which a more nuanced approach may help to resolve. Therefore, the research question addressed in this paper is: is there an association between household income and child subjective well-being when the potentially mediating effects of child deprivation, children's perceptions of family sharing practices, and child subjective material well-being are considered? Four hypotheses, which draw on the research presented above, are tested:

a) The association between a child-derived indicator of deprivation and child subjective well-being will be stronger than that between household income and child subjective well-being.

b) Children's perceptions of the fairness of family resource sharing processes and outcomes will mediate the relationship between household income and child deprivation, and child subjective material well-being. 
c) Child subjective material well-being will mediate the relationship between household income and child deprivation, children's perceptions of the fairness of family sharing practices, and child subjective well-being.

d) Household income will be significantly but indirectly associated with child subjective well-being, via child deprivation, children's perceptions of the fairness of family resource sharing, and child subjective material well-being.

\section{Data and Method}

The data used in this analysis come from the first wave of the Fair Shares and Families project survey. ${ }^{1}$ Fair Shares and Families is a longitudinal, mixed-methods study examining children's perspectives on intra-household allocation; links between intrahousehold allocation and socio-economic status; and links between child poverty, family sharing practices, and subjective well-being.

\subsection{Survey Sample}

This article draws exclusively on the first wave of the survey component of the study, which comprises data gathered by BMG, a research agency, ${ }^{2}$ from 1010 parent-child pairs. Children were aged between 10 and 16 years old at wave $1,{ }^{3}$ for which fieldwork was completed during July 2017. The sample was selected from BMG's panel, and was stratified to be representative of the population of children in England based on age, gender, and socio-economic status of the household in which the responding parent lived. Surveys took approximately twenty minutes to complete (ten minutes each for parents and children), and were completed online in respondents' homes. Participants were advised that parents and children were welcome to discuss the questions if they wanted to, but that we were interested in their own interpretation of the question - there were no 'correct' answers and it was expected that parents and children might provide different answers to similar questions if their perspectives differed. Data presented here are primarily child-supplied, although household income data was provided by parents.

\subsection{Ethical Considerations}

Ethical approval for the study was granted by the University of Leeds ethics committee. ${ }^{4}$ Data were collected and stored in a manner compliant with the ethical requirements of the University and of BMG. Participants were assured that participation in the research was voluntary, and that they did not have to answer any questions they did not want to. A small incentive was provided to participants in line with BMG's standard practices. Consent was sought from both parent (on behalf of themselves and their child) and child participants, and both parent and child participants were advised of

\footnotetext{
${ }^{1}$ Funded by the ESRC Future Research Leaders scheme, grant number ES/N015916/1.

${ }^{2}$ BMG http://www.bmgresearch.co.uk/

${ }^{3}$ The survey component is longitudinal, and will ultimately comprise three waves. The upper age of 16 for participating children at wave 1 was selected to ensure that participants are no older than 17 at the final survey wave.

${ }^{4}$ University of Leeds Ethics Committee reference number AREA-16-007.
} 
Table 1 Variable details and descriptive statistics

\begin{tabular}{|c|c|c|c|c|c|c|}
\hline Variable & Minimum & Maximum & Mean & SD & n (unweighted) & Latent variable \\
\hline $\begin{array}{l}\text { Equivalised household income } \\
\text { before housing costs (OECD } \\
\text { modified scale) (P; 'income') }\end{array}$ & 1100 & 43,300 & 16,800 & 8351 & 930 & N/A - observed \\
\hline $\begin{array}{l}\text { Child deprivation scale }(\mathrm{C} \text {; } \\
\text { 'deprivation') }\end{array}$ & 0 & 10 & 1.5 & 1.7 & 960 & N/A - observed \\
\hline $\begin{array}{l}\text { Happiness with money and } \\
\text { possessions }{ }^{\mathrm{a}}(\mathrm{C} \text {; } \\
\text { 'possessions') }\end{array}$ & 0 & 10 & 7.5 & 2.0 & 1010 & \multirow[t]{3}{*}{$\begin{array}{l}\text { Subjective } \\
\text { material } \\
\text { well-being }\end{array}$} \\
\hline $\begin{array}{l}\text { Child's rating of how well-off } \\
\text { family is }{ }^{\mathrm{b}} \text { (C; 'well-off') }\end{array}$ & 0 & 4 & 2.0 & 0.9 & 1010 & \\
\hline $\begin{array}{l}\text { Child's rating of how their } \\
\text { possessions compare to other } \\
\text { young people's }{ }^{c} \text { (C; 'peer } \\
\text { comparison') }\end{array}$ & 0 & 4 & 2.1 & 0.9 & 1006 & \\
\hline $\begin{array}{l}\text { Child's perspective on whether } \\
\text { everyone in their family gets } \\
\text { say in use of money and } \\
\text { resources }^{\text {d }} \text { (C; 'fair say') }\end{array}$ & 0 & 4 & 2.2 & 1.0 & 1010 & \multirow[t]{2}{*}{ Family sharing } \\
\hline $\begin{array}{l}\text { Child's perspective on whether } \\
\text { everyone in their family gets } \\
\text { fair share of money and } \\
\text { resources (C; 'fair outcome') }\end{array}$ & 0 & 4 & 2.5 & 1.0 & 1010 & \\
\hline SLSS: My life is going well ${ }^{\mathrm{e}}(\mathrm{C})$ & 0 & 4 & 2.9 & 0.8 & 1010 & \multirow{5}{*}{$\begin{array}{l}\text { Subjective } \\
\text { well-being }\end{array}$} \\
\hline SLSS: My life is just right (C) & 0 & 4 & 2.7 & 0.8 & 1010 & \\
\hline $\begin{array}{l}\text { SLSS: I wish I had a different } \\
\text { kind of life (reverse coded) (C) }\end{array}$ & 0 & 4 & 2.5 & 1.1 & 1010 & \\
\hline SLSS: I have a good life (C) & 0 & 4 & 3.0 & 0.7 & 1010 & \\
\hline $\begin{array}{l}\text { SLSS: I have what I want in } \\
\text { life (C) }\end{array}$ & 0 & 4 & 2.6 & 0.9 & 1010 & \\
\hline
\end{tabular}

$\mathrm{P}=$ Parent report; $\mathrm{C}=$ Child report. Phrases in brackets and speech marks indicate abbreviated variable names which are subsequently used throughout

${ }^{a}$ Rated on a $0-10$ scale, with 0 indicating lowest satisfaction and 10 indicating highest satisfaction

b Rated on a $0-4$ scale, with 0 indicating 'much better off' and 4 indicating 'much worse off'

${ }^{\mathrm{c}}$ Rated on a $0-4$ scale, with 0 indicating 'I have a lot less' and 4 indicating 'I have a lot more'

${ }^{\mathrm{d}}$ Both family sharing variables rated on a $0-4$ scale, with 0 indicating 'strongly disagree' and 4 indicating 'strongly agree'

${ }^{\mathrm{e}}$ All SLSS variables rated on the agreement scale detailed in footnote 8

how to withdraw from the study, either during or after completing the survey. No identifying details of participants were accessible to the researchers involved in analysing the data - these were removed by BMG.

\subsection{Method}

Statistical analyses were completed using Stata. Following descriptive and factor analysis, the analyses were performed using Stata's structural equation modelling (SEM) 


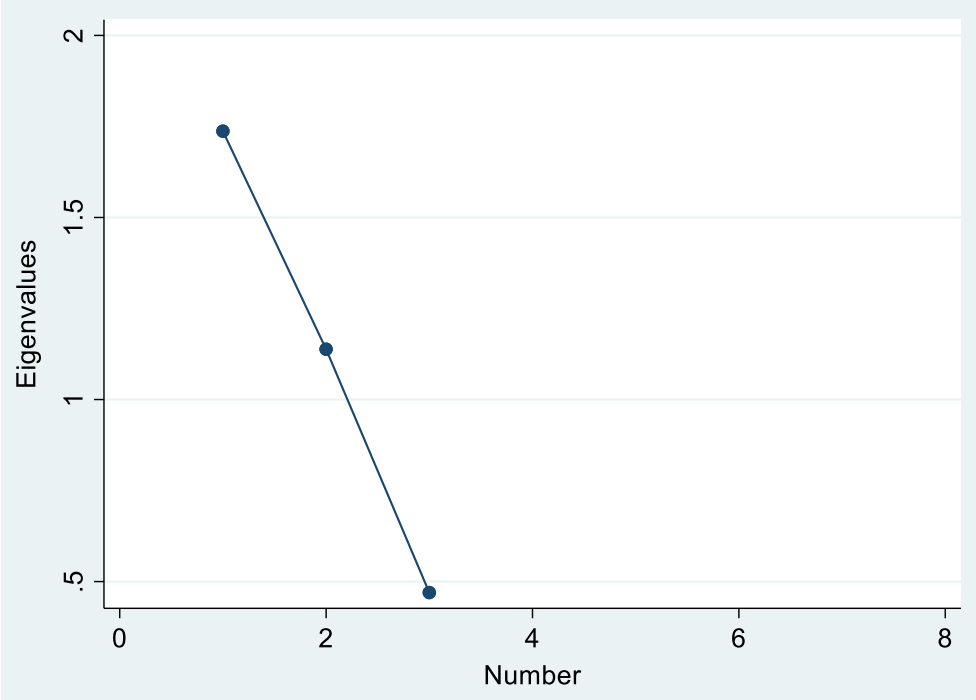

Fig. 1 Eigenvalues plot

(-sem-) commands. SEM incorporates a wide range of models usually expressed as path diagrams which illustrate the relationship(s) between variables in the model (see Bollen et al. 2013 and Nachtigall et al. 2003 who outline the capabilities of SEM). Models can include both observed and latent variables; the analysis presented below is based on a mixture of both variable types, detailed in Table 1. Observed variables (e.g. income) are based directly on the variables included in the dataset, while latent variables (e.g. subjective well-being) are estimated within the model from proxy variables included in the dataset. Latent variables have the advantage of including measurement error in calculations - something which is not possible with standard linear regression models. Similarly, SEM has the advantage over linear regression of allowing the examination of multiple paths between variables - that is, rather than having a single outcome variable and multiple predictors, SEM allows for interrelationships among predictor variables. This approach is uniquely suited to address the hypotheses detailed above. It enables an examination of direct effects - i.e. the relationship between each predictor and the outcome variable - and indirect effects - i.e. the relationship between a predictor and the outcome variable via other variables. For example, in the analysis presented here it is possible to examine not only the direct association between income and subjective wellbeing, but also the indirect association between income and subjective well-being via subjective material well-being. Weights were constructed to ensure the data were representative of children aged 10-16 in England based on gender, age and socio-economic status - unless stated otherwise, all analyses presented here are based on weighted data.

\subsection{Variables}

Table 1 provides descriptive statistics for the variables used in this analysis. The next section provides a more detailed justification for the specific dimensions included. In addition to these variables, child age $(\min =10, \max =16$, mean $=13, n=1010)$ and child 
gender $(\mathrm{f}=52 \%, \mathrm{~m}=48 \%$, identifying as something else $=0.1 \%, \mathrm{n}=1010)$ were used as controls in the analysis. One of the variables - the Child Deprivation Scale (CDS) - is a composite variable based on the sum of items lacking from a total of ten, based on an index of child deprivation established in previous research (Main 2013). These items are based on children's own perceptions of their material needs, and are equally weighted in the final index. Details of the background to this index can be found in Main (2013) and Main and Pople (2011). The last five variables form a modified version of the Student's Life Satisfaction Scale (Huebner 1991; modified by Rees et al. 2010).

The final column of Table 1 shows which variables are observed, and which predict latent variables in the structural equation model. Latent variables in the model include subjective material well-being, family sharing, and subjective well-being (see Fig. 1 for details of the pathways between these variables).

All variables apart from child age and child gender were standardised for inclusion in the model, although non-standardised ranges are presented in Table 1 for ease of interpretation. Age and gender were not standardised as these were included as control variables rather than as variables of substantive interest to the research questions. The rationale for including these are based on previous research finding significant but mixed associations between SWB and gender (e.g. The Children's Society, The Children's Society 2017a, b; Rees and Main 2016); and significant declines in SWB associated with age (e.g. Currie et al. 2008).

\subsection{Dimensions of Poverty}

The aim of this analysis is to test whether different dimensions of child poverty characterised by household factors, child-specific factors, and children's reports on their subjective experiences of material resources and resource sharing - can help in understanding the relationship between child poverty and subjective well-being. Several dimensions of child poverty are identified in the hypotheses. These comprise household income; child deprivation; child perceptions of family sharing; and child subjective material well-being. While all of these fall within the overarching concept of 'material well-being', there are good theoretical and empirical reasons to treat them as separate dimensions within this concept. These include that Main (2013) found that child deprivation was distinct from household income in its impacts on children's subjective well-being; Bradshaw and Finch (2003) found that subjective poverty, income, and deprivation identified different groups of people as in poverty, with only a small core found to be poor on all three dimensions; and studies of the fairness of intra-household allocation have found inequities across the income distribution - not only among lowincome households. This is not to say that correlations do not exist between these dimensions; rather, that in order to understand the complex association between child poverty and subjective well-being, there may be value in separating out these factors.

Exploratory factor analysis of the standardised variables was used to explore the empirical basis of treating these dimensions separately in this dataset. In line with the guidance of Fabrigar et al. (1999), a maximum likelihood approach was used and, since the factors represent domains of the overall concept of material well-being, oblique rotation was used meaning that the factors were allowed to correlate. Three factors were identified, with loadings shown in Table 2. Figure 1 shows the scree plot for the identified factors, which supports the retention of all three as there is no levelling off of 
Table 2 Factor loadings

\begin{tabular}{llll}
\hline Variable & $\begin{array}{l}\text { Factor 1 (Subjective } \\
\text { material well-being) }\end{array}$ & $\begin{array}{l}\text { Factor 2 (Household income } \\
\text { and child deprivation) }\end{array}$ & $\begin{array}{l}\text { Factor 3 } \\
\text { (Family sharing) }\end{array}$ \\
\hline $\begin{array}{l}\text { Income } \\
\text { Deprivation }\end{array}$ & 0.58 & \\
Possessions & 0.14 & 0.59 & 0.33 \\
Well-off & 0.31 & 0.18 & \\
Peer comparison & 1.02 & 0.52 & 0.55 \\
Fair say & & & 0.80 \\
Fair outcome & & & \\
\hline
\end{tabular}

the plot. These factors broadly fit with the theoretical basis identified above; loadings on factor 1 are primarily related to subjective material well-being, factor 2 to objective material well-being (household income and child deprivation), and factor 3 to perceptions of fairness in family sharing processes and outcomes. Some issues with this analysis must be acknowledged. The data fail to meet many of the good-practice criteria in relation to factor analysis. Specifically, there are insufficient variables to meet the minimum criteria which, Fabrigar et al. (1999) highlight, are commonly recommended. This analysis is reported as, despite the limitations, it offers some support and context for the SEM analysis detailed below. However, results should be interpreted tentatively and have been used as guidance rather than determining considerations in how the SEM analysis proceeded.

Fabrigar et al. (1999) recommend that interpretations of factor analysis should draw on substantive theoretical considerations as well as statistical ones. Therefore, given the tentative support for treating objective material well-being, subjective material wellbeing, and perceptions of family sharing as separate dimensions in the data, alongside the theoretical bases identified above for examining these factors separately, analysis proceeded based on these factors. For the objective material well-being factor, household income and child deprivation were included as separate indicators rather than as co-predictors of a latent 'objective material well-being' variable, based on the findings reported above indicating that their effects on child subjective well-being have consistently been found to be substantially different. This was also determined to be important as household income was reported by parents, while child deprivation was childreported.

\subsection{Findings}

Figure 2 shows the structural equation model with the coefficients for each pathway marked. Coefficients can be interpreted as the change in the predicted variable associated with a one-unit change in the predictor. ${ }^{5}$ For ease of interpretation of the model in the diagram below (Fig. 2), all variables were coded so that higher scores were

\footnotetext{
5 The terms 'predictor', and 'predicted' or 'outcome', are used here to indicate the ordering of variables in the model. No claims are intended in relation to causality, which cannot be established based on cross-sectional data as used here.
} 


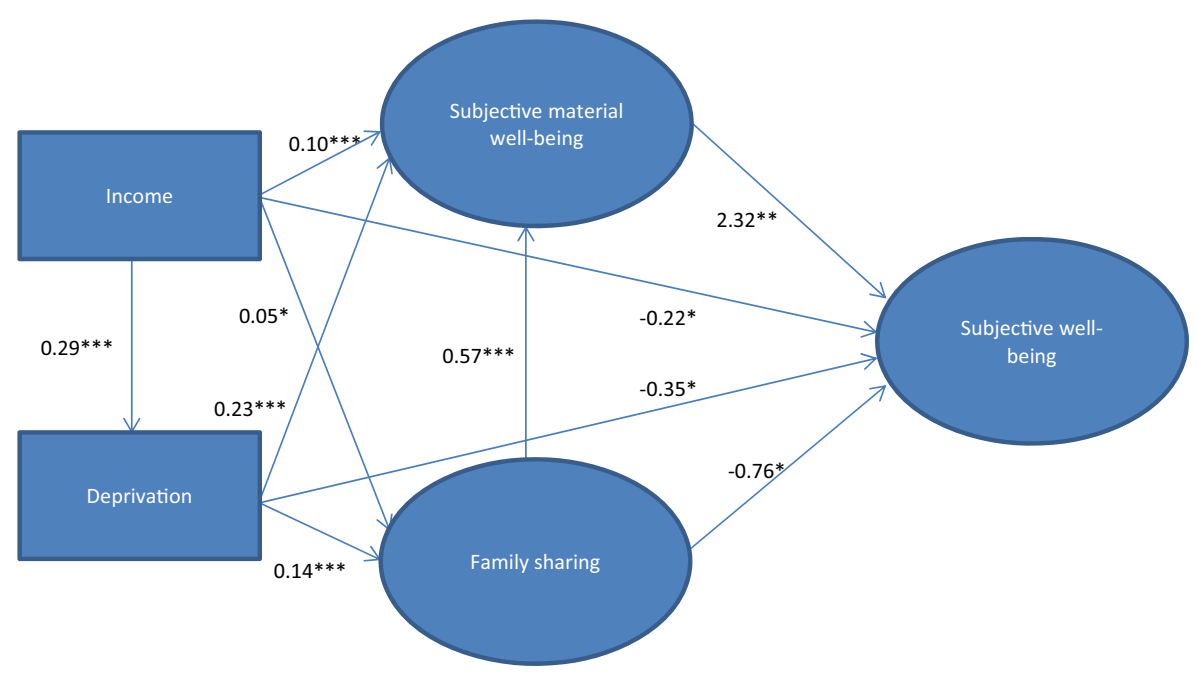

Fig. 2 Structural equation model showing the associations between household income and child deprivation, children's perceptions of family sharing, subjective material well-being, and subjective well-being. All variables shown in Fig. 2 are standardised. $\mathrm{SRMR}=0.03 ; \mathrm{CD}=0.62$. NS: Non-significant association. *: Significant at the $p<0.05$ level. **: Significant at the $p<0.01$ level. ***: Significant at the $p<0.001$ level

indicative of a better situation - resulting in some variables being reverse coded (e.g. scores on the deprivation variable, calculated by summing the number of items children reported lacking and wanting access to, were reverse coded so that in the model below, higher scores indicate lower levels of deprivation). As a result, negative coefficients indicate a qualitatively negative association (i.e. the child fares worse on the predicted variable) and positive coefficients indicate a qualitatively positive association (i.e. the child fares better on the predicted variable).

Bollen et al. (2013) note that the standard goodness-of-fit statistics used in assessing SEMs are not designed for use with complex survey data, highlighting various areas of consensus and debate around the use of SEMs with such data. Indeed, when weights or complex sample analyses are performed in Stata, the indices (such as RMSEA, TLI and CFI) which are often used to assess goodness-of-fit are not provided to avoid their misuse. Instead, maximum likelihood-based standardised root mean square residual (SRMR) and the coefficient of determination (CD) are calculated. For the SRMR, a perfect fit is equal to 0 and a common cut-off indicating that the fit is acceptable is under 0.08 (see $\mathrm{Hu}$ and Bentler 1999). For the CD, a perfect fit is equal to 1 and the number can be interpreted in a similar manner to the $r$ squared statistic for linear regression models - i.e. it indicates the proportion of variation in the outcome variable explained by the model. ${ }^{6}$

As noted above, a significant advantage of SEM methods over linear regression is the capability to examine not only direct effects but also indirect effects via which predictor variables are associated with the outcome variable. Figure 3 summarises the direct, indirect and total effects on subjective well-being of all the predictor variables in

\footnotetext{
${ }^{6}$ See https:/www.stata.com/manuals/semexample4.pdf for details of the goodness-of-fit statistics Stata produces for SEMs under different conditions.
} 


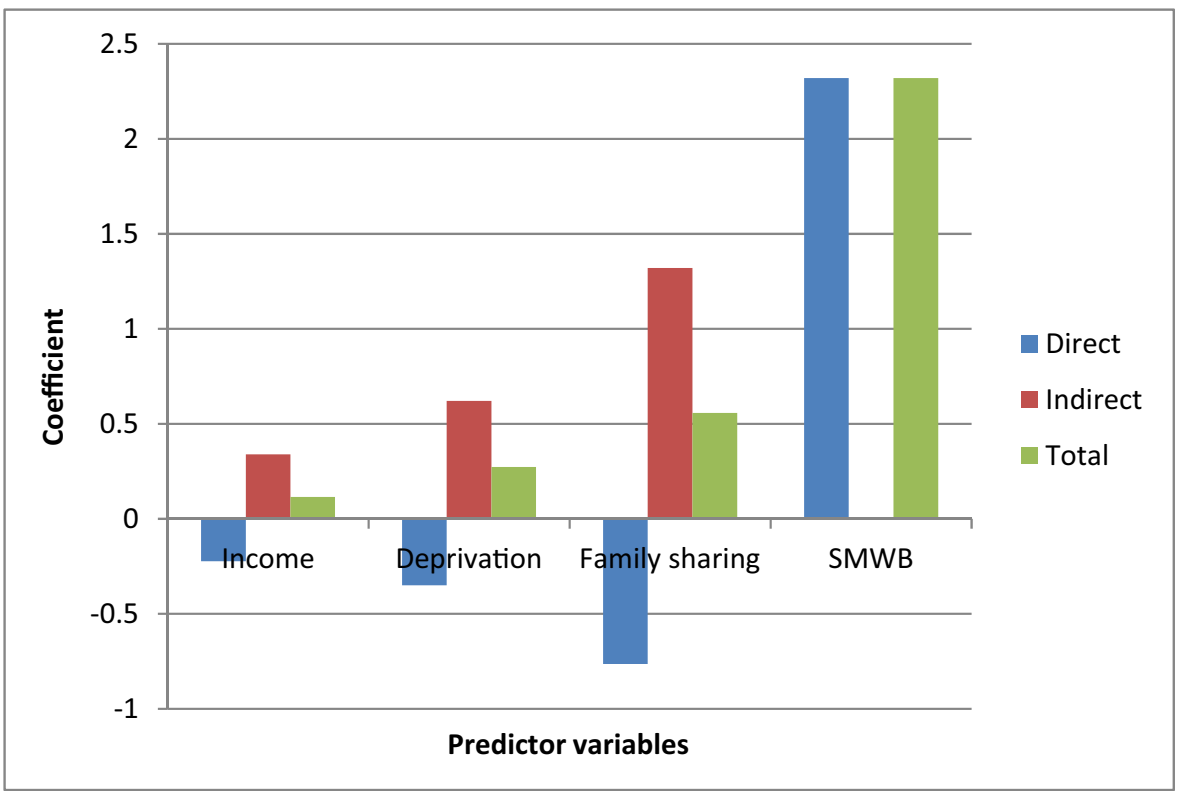

Fig. 3 Direct, indirect and total effects on SWB. All figures based on standardised variables, to enable direct comparisons between the effect sizes

the model (n.b. there are no indirect effects for subjective material well-being as this is only included as a direct predictor of subjective well-being; effect sizes are directly comparable as all variables were standardised for the model).

All pathways in the structural model are significant, ${ }^{7}$ confirming that the range of variables included are significantly associated with each other and with subjective well-being. The model is a good fit, with the SRMR of 0.03 well below the common cut-off threshold of 0.08 . The CD indicates that the model explains $62 \%$ of the variation in subjective well-being. Breaking this down by effects of the constituent variables as shown in charts $1,2.2 \%$ of the overall variation in subjective well-being is associated with income; $5.2 \%$ is associated with deprivation; $10.7 \%$ is associated with perceptions of family resource sharing; and $44.5 \%$ is associated with subjective material well-being.

Returning to the hypotheses detailed above:

a) The model confirms findings from previous research that deprivation (based on child-derived indicators) has a stronger association with subjective well-being than household income. The total effects of household income on subjective well-being were $b=0.12 * * *$ (i.e. an increase of one standardised unit of income was associated with an increase of 0.12 of a standardised unit of subjective well-being), while the effects of deprivation were $b=0.27 * * *$ (bearing in mind that deprivation was reverse coded, so one standardised unit less deprivation was associated with a 0.27 unit increase in subjective well-being).

\footnotetext{
${ }_{7}^{7}$ Age and gender are not included in this discussion; age was found, as anticipated, to have a significant negative association with SWB, while gender did not have a significant association.
} 
b) The model confirms that children's perceptions of family resource sharing practices mediate the association between household income and child deprivation and subjective material well-being. Perceptions of how families share their resources were predicted (although at $\mathrm{b}=0.05 *$ for income and $\mathrm{b}=0.14 * * *$ for deprivation, coefficients were rather small) by income and deprivation. The coefficient for the association between perceptions of family sharing practices and subjective material well-being $(b=0.57 * * *)$ was much larger than those for the direct pathways between income $(b=0.10 * * *)$ or deprivation $(b=0.23 * * *)$ and subjective material well-being.

c) The model confirms that subjective material well-being mediates the relationship between household income and child deprivation, perceptions of family sharing practices, and subjective well-being. Subjective material well-being explained far more of the variation in subjective well-being - 44\% - than the other variables combined. This lends support to the argument detailed above, that subjective measures are not fully independent as they are interrelated based on their focus on subjectivity, and co-determined by personality factors. However, as detailed above, significant pathways existed between the other predictors and subjective material well-being - i.e. indirect as well as direct associations between these predictors and the outcome were found. Coefficients for these associations were income $b=0.22 * * *$, deprivation $b=0.32 * * *$ and perceptions of family sharing $\mathrm{b}=0.57 * * *$.

d) The model confirms that income was associated with subjective well-being indirectly, via deprivation, perceptions of family resource sharing practices, and subjective material well-being. However, this hypothesis was only partially supported as income also had a direct and, interestingly, negative association with subjective well-being $(b=-0.22 *)$. As a result, the total effects of income on subjective well-being were a result of a combined positive impact via the other predictor variables (i.e. children in households with a higher income reported lower levels of deprivation, higher levels of fairness in how family resources are shared, and higher levels of subjective material well-being). But these positive associations were moderated by the negative direct effect of income on subjective well-being. This somewhat surprising finding is discussed in more detail below - and is mirrored in the direct effects of deprivation and perceptions of family sharing on subjective well-being. It goes some way to explaining the insignificance of income in linear regression models used in previous research noted above, since effects in different directions will cancel each other out in the overall analysis.

\section{Discussion and Conclusions}

The purpose of this article was to examine whether a more nuanced approach would help explicate the relationship between household income and child subjective wellbeing. Previous research (e.g. Cooper and Stewart 2013) demonstrates the importance of income to children's long-term outcomes; but given that children in low-income households report shame, stigma, and an awareness of missing out on the things their peers take for granted (Ridge 2002; Main and Pople 2011), we would also expect to see a significant association with subjective well-being during childhood. As noted above, 
previous studies have struggled to identify this link. The more nuanced approach used in this analysis proves helpful in understanding this issue. While income does have a significant association with subjective well-being, the relationship is complex. Direct effect and indirect effects in opposite directions appear to cancel each other out, potentially resulting in an obscuring of the association in analyses which do not adequately capture its complexity.

The negative coefficients of household income, child deprivation, and fairness of family sharing in their direct relationships with subjective well-being bear some initial consideration. It should be noted that the significant positive associations between each of these variables and subjective material well-being indicates that for the majority of children, being in a higher income household, being less deprived, and perceiving family resources to be shared fairly are associated with higher subjective material well-being. We would therefore expect only a small number of children to be in the position of living in a higher income household and/or being less deprived than their peers to nonetheless report lower subjective material well-being. However, for this small group of children it is interesting that the direct relationship household income and child deprivation have with subjective well-being is a negative one. This lends some support to the conclusion that children's own interpretations of their material conditions can influence the relationship between material conditions and subjective well-being, and are a vital component in understanding this relationship. That is, whatever their 'objective' material living conditions, if children do not judge themselves to be in a good material situation, these conditions will not translate into higher subjective well-being. Further exploration of the 'high income, low deprivation, low subjective well-being' group would be a valuable avenue to pursue, to gain a better understanding of factors which might prevent a higher household income from translating into children's higher satisfaction with material conditions.

This section firstly provides some reflections on the meanings of these results. Two themes - multi-dimensional poverty measurement and the issue of choice and freedom in understanding child poverty - are discussed. A rights-based approach to child poverty measurement is proposed, focusing on participation as well as provision and protection. Finally, limitations of this research are detailed, and recommendations are made for future research directions.

\subsection{The Multidimensional Nature of (Child) Poverty}

The complex nature of the associations between the variables included in this analysis underscores the importance of conceptualising and measuring child poverty as multidimensional. It has long been established that different groups are captured by measures of different dimensions of poverty (e.g. Bradshaw and Finch 2003); and this has been incorporated into various approaches to poverty measurement through a deconstruction of deprivation on different dimensions (Gordon and Nandy 2012) and/or through examining breadth and depth of poverty using a 'dashboard' approach (Alkire 2011; Bailey et al. 2017). The findings presented here address a slightly different consideration: that of how different dimensions of material well-being interrelate and combine to influence levels of subjective well-being. The results indicate that these are important concerns - the use of unidimensional indicators and methods which do not consider the complex interrelationships between indicators may obscure and confound findings. Just as there are compelling reasons that we might not expect high levels of overlap between 
the groups captured by measures of different dimensions of poverty, there are compelling reasons why different dimensions of poverty may impact differently on multiple outcomes of interest. This does not undermine the importance of any particular indicators - money, the most commonly-used unidimensional indicator of poverty, matters. But it does highlight the importance of acknowledging the limitations of such measures, and attending to the complexities of real lives. This is especially relevant to children's situations, since (as noted above) their access to and control over resources is realised in much more constrained circumstances than most approaches to (child) poverty measurement acknowledge. This point is taken up further in the next section.

An important caveat here is that an emphasis on the multidimensional nature of child poverty must not be interpreted as a legitimisation of the use of eclectic bundles of un- or under-theorised dimensions. Gordon and Nandy (2012) stress the importance of a strong theoretical basis for the definition and measurement of poverty, highlighting the risk of diluting the concept to the point where anything can be included. This issue is also of importance in relation to the point raised in the literature review and confirmed in this analysis - that certain types of predictor are inherently likely to be much more strongly associated with outcomes than other types of predictor. In this case, subjective indicators of material well-being are inherently likely to be more strongly linked than objective indicators to subjective indicators of well-being, and this cannot convincingly be interpreted as an indication that these are more important than objective indicators. A strong theory underpinning valid and reliable indicators, and the likely associations between these indicators as well as between indicators and outcomes of interest, is vital. Such underpinnings are necessary to the production of compelling findings with the capacity to inform positive and meaningful change, both in academic approaches to the study of poverty and, infinitely more importantly, to children's lives. Existing theories provide an excellent starting point for this but, as noted above, are not always adequately calibrated to children's unique social position. Much work remains to be done in relation to developing theory, definitions, and measures of poverty which are truly child-centric - this is discussed next.

\subsection{Choice and Freedom: Rethinking the Concept of Poverty for Children}

The complexity in the relationship between household income and child subjective well-being lends support to the position that children cannot be treated as passive adjuncts to the adults they live with in understandings of child poverty. As highlighted above in the literature review, social studies of childhood have revealed children to be active agents in constructing and negotiating their lives. This study contributes to the growing body of literature confirming that children exercise this agency in developing their understandings and negotiating their experiences of poverty and their material living conditions (see Ridge 2002; Main and Pople 2011; Redmond et al. 2016; Lau and Bradshaw 2016; Gross-Manos and Ben Arieh 2016; and Smith and Main 2017). This point is overwhelmingly ignored in studies of child poverty. But, as also highlighted in the literature review, approaches to theorising poverty based on adult-centric assumptions about power and agency are no more suitable than are assumptions that children have no power and agency. This raises an important tension - that of how to acknowledge the constraints which limit children's exercise of power and agency, while simultaneously acknowledging children's active roles in shaping social and personal understandings and experiences of poverty. 
The assumption implicit in dominant theories of poverty, and in the translation of those theories into definitions and measures, has tended to be that power and agency in relation to material well-being are exercised via control over monetary resources. This is the basis of using income as a measure of poverty or, more broadly, of living standards. This assumption is both gendered (Bennett 2013) and, pertinently for this analysis, adult-centric. Pahl's (1989) work was vital in opening the 'black box' of the household economy to highlight gender inequalities. But despite overwhelming evidence of inequity and continuing efforts to understand what goes on within households (e.g. Bennett 2013; Main and Bradshaw 2018), for many studies the box remains firmly closed. This is not to say that studies at the level of the household are not valuable - they undeniably offer a great deal of important evidence on the impacts of poverty. But more could be done within such studies to acknowledge the limitations of this approach, and there is an urgent need for more studies which continue to identify the multifarious ways in which intra-, as well as inter-, household distribution affects people's lives and opportunities. Individualised, and arguably simplistic, notions of power and agency which do not consider the deeply relational and social contexts in which lives happen are not adequate in capturing the complexities of poverty, especially - but not only for children. The results presented here underscore the points raised in the literature review that study of poverty and social studies of childhood have so far had limited contact, but that there is great potential for cross-fertilisation; and that intra-household allocation should be a central consideration in the understanding of child poverty. Children can and do exercise power and agency, but in ways which are not captured by current, adult-centric approaches to understanding child poverty.

\subsection{Children's Rights: a Way Forward?}

These findings have relevance for research, policy and practice in the fields of child poverty and well-being. Firstly, whilst adequate household income is by no means a sufficient condition for promoting children's subjective well-being, it is absolutely a necessary condition for doing so. The primary means by which families obtain resources is money, and in her related research Knies (2017) found that increases in income are particularly important for promoting the subjective well-being of young people in poorer households. Governments are unlikely to achieve improvements in children's subjective well-being (or indeed, their objective well-being) unless they demonstrate a commitment through policy to increasing the incomes of the poorest families - something which runs counter to current policy in the UK (see Bradshaw et al. 2017; Main and Bradshaw 2018). Secondly, but no less importantly, these findings highlight the importance of prioritising children's reports and perspectives in how child poverty is researched, and in the development of policies with a higher chance of achieving poverty reduction. As noted above, the UNCRC enshrines children's right to express their views and have those views respected. Yet children's voices are notably absent in academic theories and policy processes around child poverty. The promotion of children's voices does not mean that other perspectives those of parents, experts, and other professionals involved in children's lives - are not important; but they cannot represent the entirety of children's experiences and are not sufficient without also hearing and incorporating children's voices.

Taken together, these implications result in a more nuanced approach to understanding child poverty - one which draws on different measures and types of measure; and one which combines multiple perspectives - including those of children themselves. 
Undoubtedly, this creates additional complexity in to how child poverty is theorised, measured, and addressed. But it also opens up opportunities to understand and address child poverty in a more holistic, and ultimately more effective, manner.

\subsection{Limitations and Future Directions}

The research presented here, as noted in the background discussion, is informed by four fields of study, some of which have not previously been integrated. An important limitation of this study is therefore that although it builds on previous work (see Main 2017), the integration of these fields remains at an early stage. This research contributes to the process of problematising adult-centric theories of poverty - much more work is necessary in order to develop truly child-centric approaches. Children's perspectives are included here at the level of measurement rather than definition or theory. A valuable contribution to this field would be a detailed analysis of how different theories of poverty might be developed to better incorporate children's unique social and developmental status, especially in relation to choice and autonomy as they inform understandings of both poverty and subjective well-being.

The findings presented here draw on a representative sample of children in England, including data gathered from one parent as well as from the child. Data on child poverty and well-being based on a child-centric research design remain rare, and the analysis draws on the best available data on this topic. However, the data are not representative of parents (in particular, the parent sample is not balanced for gender as this was not achievable alongside generating a sample representative of children, within the constraints of the project). Furthermore, the majority of the data collected relate to one household and therefore do not capture the complexities which increasing numbers of children experience when living across multiple households. Since this analysis draws on cross-sectional data, it does not reflect changes in access to resources over time. Longitudinal data on children's access to resources, surveys including all household members (or as many as practicably possible where surveys may not be adaptable to very young children), and qualitative and mixed methods research to gain a better understanding of children's lives and access to resources in diverse living situations as well as to develop a broader range of high-quality survey questions designed to capture this complexity, would all form very valuable contributions to this developing field of research. Such data will be produced through the Fair Shares and Families project, which will enable the continued examination of these issues.

Open Access This article is distributed under the terms of the Creative Commons Attribution 4.0 International License (http://creativecommons.org/licenses/by/4.0/), which permits unrestricted use, distribution, and reproduction in any medium, provided you give appropriate credit to the original author(s) and the source, provide a link to the Creative Commons license, and indicate if changes were made.

\section{References}

Alkire, S. (2011). Multidimensional poverty and its discontents. OPHI Working Paper No. 46. Oxford: OPHI. Alkire, S. (2015). The capability approach and well-being measurement for public policy. OPHI Working Paper No. 94. Oxford: OPHI.

Bailey, N., Fahmy, E., \& Bradshaw, J. (2017). The multi-dimensional analysis of social exclusion. In G. Bramley \& N. Bailey (Eds.), Poverty and social exclusion in the UK: Volume 2, The dimensions of disadvantage. Bristol: Policy Press. 
Barrington-Leigh, C. (2010). Economic inequality and subjective well-being: Is inequality good for the rich?. Working paper. Vancouver: University of British Colombia.

Bennett, F. (2013). Researching within-household distribution: Overview, developments, debates, and methodological challenges. Journal of Marriage and Family, 75(3), 582-597.

Bollen, K. A., Tueller, S., \& Oberski, D. (2013). Issues in the structural equation modelling of complex survey data. In Proceedings of the $59^{\text {th }}$ World Statistics Congress. Hong Kong.

Bradshaw, J. (2016). The well-being of children in the UK. Bristol: Policy Press.

Bradshaw, J. (2018). The unit of analysis in poverty measurement: Household of family?. On Jonathan Bradshaw Blog available online at http://jonathanbradshaw.blogspot.co.uk/2018/03/the-unit-of-analysis-in-poverty.html.

Bradshaw, J., \& Finch, N. (2003). Overlaps in dimensions of poverty. Journal of Social Policy, 32(4), 513-525.

Bradshaw, J., Chzhen, K., \& Main, G. (2017). Child poverty in the UK. In B. Cantillon, Y. Chzhen, S. Handa, \& B. Nolan (Eds.), (2017) Children of austerity: Impact of the great recession on child poverty in rich countries. Oxford: OUP.

Casas, F. (2011). Subjective social indicators and child and adolescent well-being. Child Indicators Research, $4(4), 555-575$.

Chzhen, Y., \& Ferrone, L. (2017). Multidimensional child deprivation and poverty measurement: Case study of Bosnia and Herzegovina. Social Indicators Research, 131(3), 999-1014.

Chzhen, Y., Bruckhauf, Z., Toczydlowska, E., Elgar, F. J., Moreno-Maldonado, C., Stevents, G. W. J. M., Sigmundova, D., \& Gariepy, G. (2017). Multidimensional poverty among adolescents in 38 countries: Evidence from the health behaviour on school-aged children (HBSC) 2013/14 study. Child Indicators Research online first, 11, 729-753. https://doi.org/10.1007/s12187-017-9489-0.

Cooper, K. \& Stewart, K. (2013). Does money affect Children's outcomes? A systematic review. Report for the Joseph Rowntree Foundation. York: JRF.

Cummins, R. A. (2000). Personal income and subjective well-being: A review. Journal of Happiness Studies, $1(2), 133-158$.

Currie, C., Gabhainn, S. N., Godeau, E., Roberts, C., Smith, R., Currie, D., Picket, W., Richter, M., Morgan, A., \& Barnekow, V. (2008). Inequalities in Young People's Health: Health Behaviour in School-aged Children (HBSC) international report from the 2005/2006 survey. Health Policy for Children and Adolescents no. 5. Copenhagen: World Health Organisation.

Dermott, E., \& Main, G. (2018). Poverty and social exclusion in the UK-volume 1: The nature and extent of the problem. Bristol: Policy Press.

Fabrigar, L. R., Wegnener, D. T., MacCallum, R. C., \& Strahan, E. J. (1999). Evaluating the use of exploratory factor analysis in psychological research. Psychological Methods, 4(3), 272-299.

Foster, J., Seth, S., Lokshin, M., \& Sajaia, Z. (2013). A unified approach to measuring poverty and inequality: Theory and practice. Washington: World Bank.

Gordon, D., \& Nandy, S. (2012). Measuring child poverty and deprivation. In A. Minujin \& S. Nandy (Eds.), Global child poverty and well-being: Measurement, concepts, policy and action. Bristol: Policy Press.

Goswami, H. (2014). Children's subjective well-being: Socio-demographic characteristics and personality. Child Indicators Research, 7(1), 119-140.

Griggs, J., \& Walker, R. (2008). The costs of child poverty for individuals and society: A literature review. York: Joseph Rowntree Foundation.

Gross-Manos, D. (2015). Material deprivation and social exclusion of children: Lessons from measurement attempts among children in Israel. Journal of Social Policy, 44(1), 105-125.

Gross-Manos, D. and Ben-Arieh, A. (2016) 'How Subjective Well-being is Associated with Material Deprivation and Social Exclusion in Israeli 12-Year-Olds'. In American Journal of Orthopsychiatry. https://doi.org/10.1037/ort0000160.

Headey, B., \& Wooden, M. (2004). The effects of wealth and income on subjective well-being and ill-being. Economic Record, 80(S1), S24-S33.

Hjelm, L., Ferrone, L., Handa, S. \& Chzhen, Y. (2016). Comparing approaches to the measurement of multidimensional child poverty. Office of Research-Innocenti Working Paper WP-2016-29.

Hu, L., \& Bentler, P. M. (1999). Cutoff criteria for fit indexes in covariance structure analysis: Conventional criteria versus new alternatives. Structural Equation Modeling: A Multidisciplinary Journal., 6(1), 1-55.

Huebner, E. S. (1991). Initial development of the Student's life satisfaction scale. School Psychology International, 12(3), 231-240.

Katic, I. \& Ingram, P. (2017). Income inequality and subjective well-being: Toward an understanding of the relationship and its mechanisms. In Business and Society. Online First. https://doi.org/10.1177 /0007650317701226. 
Knies, G. (2011). Life satisfaction and material well-being of young people in the UK'. In Understanding society: Early findings from the first wave of the UK's household longitudinal study. http://research. understandingsociety.org.uk/findings/early-findings.

Knies, G. (2017). Income effects on children's life satisfaction: Longitudinal evidence for England. ISER Working Paper no. 2017-02. Available online from https:/www.iser.essex.ac.uk/research/publications/workingpapers/iser/2017-02.

Lau, M. \& Bradshaw, J. (2016). Material well-being, social relationships, and children's overall life satisfaction in Hong Kong. In Child Indicators Research vol.

Mack, J., \& Lansley, S. (1985). Poor Britain. London: George Allen and Unwin.

Main, G. (2013). A child-derived material deprivation index. Unpublished $\mathrm{PhD}$ thesis submitted to the University of York September 2013.

Main, G. (2017) 'Child Poverty and Subjective Well-being: The impact of children's perceptions of fairness and involvement in intra-household sharing'. In Children and Youth Services Review. https://doi. org/10.1016/j.childyouth.2017.06.031.

Main, G., \& Bradshaw, J. (2014). Children's necessities: Trends over time in perceptions and ownership. Journal of Poverty and Social Justice, 23(3), 193-208.

Main, G., \& Bradshaw, J. (2016). Child poverty in the UK: Measures, prevalence and intra-household sharing. Critical Social Policy, 36(1), 38-61.

Main, G., \& Bradshaw, J. (2018). Improving Lives? Child poverty and social exclusion. In E. Dermott \& G. Main (Eds.), Poverty and social exclusion in the UK-Volume 1: The nature and extent of the problem. Bristol: Policy Press.

Main, G., \& Pople, L. (2011). Missing out: A child-centred analysis of material deprivation and subjective well-being. London: The Children's Society.

Middleton, S., Ashworth, K., \& Braithwaite, I. (1997). Small fortunes: Spending on children, childhood poverty and parental sacrifice. York: Joseph Rowntree Foundation.

Nachtigall, C., Kroehne, U., Funke, F., \& Steyer, R. (2003). (Why) should we use SEM? Pros and cons of structural equation modelling. Methods of Psychological Research Online., 8(2), 1-22.

Pahl, J. (1989). Money and marriage. London: MacMillan.

Pantazis, C., Gordon, D., \& Levitas, R. (2006). Poverty and social exclusion in Britain: The millennium survey. Bristol: Policy Press.

Rablen, M. D. (2010). The promotion of wellbeing: A primer for policymakers. Economics and finance working paper series WP no. 10-25. London: Brunel.

Redmond, G. (2008). Child poverty and child rights: Edging towards a definition. Journal of Children and Poverty, 14(1), 63-82.

Redmond, G., Skattebol, J., Saunders, P., Lietz, P., Zizzo, G., O’Grady, E., Tobin, M., Thomson, S., Maurici, V., Huynh, J., Moffat, A., Wong, M., Bradbury B. \& Roberts, K. (2016). Are the kids alright? Young Australians in their middle years. Final report of the Australian child well-being project. Available online from http://www.australianchildwellbeing.com.au/sites/default/files/uploads/ACWP Final Report 2016 Full.pdf

Rees, G., \& Main, G. (2016). Children's views on their lives and well-being in 15 countries: $\bar{A}$ report on the Children's worlds survey, 2013-14. York: Children's Worlds Project (ISCWeB).

Rees, G., Goswami, H., \& Bradshaw, J. (2010). Developing an Index of children's subjective well-being in England. London: The Children's Society.

Rees, G., Pople, L. and Goswami, H. (2011) Understanding Children's Well-being: Links between family economic factors and children's subjective well-being. London: The Children's Society.

Ridge, T. (2002). Childhood poverty and social exclusion. Bristol: Policy Press.

Sen, A. (1985). Commodities and capabilities. Oxford: OUP.

Sen, A. (1999). Development as freedom. Oxford: OUP.

Smith, A., \& Main, G. (2017). Missing out: Developing a child-derived index of child deprivation'. Presentation at the International Society for Child Indicators conference Montreal, July 2017.

The Children's Society. (2017a). The good childhood report 2017. London: The Children's Society.

The Children's Society. (2017b). Understanding childhoods: Growing up in hard times. London: The Children's Society.

Townsend, P. (1979). Poverty in the United Kingdom. London: Allen Lane and Penguin Books.

Uprichard, E. (2008). Children as 'beings and becomings': Children, childhood and temporality. Children and Society, 44(4), 303-313.

Wilkinson and Pickett. (2009). The spirit level. London: Penguin.

Woodhead, M. (2009). Child development and the development of childhood. In J. Qvortup, W. A. Corsaro, \& M. S. Honig (Eds.), The Palgrave handbook of childhood studies. London: Palgrave Macmillan. 